\title{
Study on the Velocity of Partially Submerged Landslide
}

\author{
Wang Yang ${ }^{1, *}$, Tang Yang ${ }^{1}$, Cao Ying ${ }^{1}$, Li De-ying ${ }^{1}$ and Wang Wei ${ }^{2}$ \\ ${ }^{1}$ Engineering Faculty, China University of Geosciences, 430074, Wuhan, Hubei, China \\ ${ }^{2}$ Department of Civil and Structural Engineering, Graduate School of Engineering, Kyushu University, 819-0395, Fukuoka, Japan
}

Received 10 March 2014; Accepted 2 August 2014

\begin{abstract}
Hydraulic resistance is one of the most important factors which affect the velocity of the partially submerged landslide when it moves into river at a high speed. In this paper, an experiment system was designed including a water tank, a moving frame fixed over the tank with liquid level sensors, blocks, and velocity control apparatus. Six blocks with different areas were used for experiments and each block moved at five different velocities in water tank. Test results showed that the increment of the pressure head was proportional to the square velocity of submerged block. Based on that, the total water pressure and corresponding hydraulic resistance of the moving block in water tank were obtained, and the latter was used to analyze hydraulic resistance acting on partially submerged landslide. Method of slice was applied to calculate the forces of landslide with curved slip surface. The dynamics and kinematics equation of landslide were used to calculate the velocity. Taking the Dayantang landslide as an example, velocities with different travel distance were obtained. The results showed that the maximum velocity of Dayantang landslide considering hydraulic resistance was $18.6 \%$ less than that without considering hydraulic resistance.
\end{abstract}

Keywords: partially submerged landslide; velocity; pressure head; hydraulic resistance

\section{Introduction}

Impoundment of reservoir can cause catastrophic bank landslide events. For instance, Vajont landslide (Mueller, 1968) in Italy and Qianjiangping landslide in China (Wang et al., 2004) moved into reservoir at a high speed after the raise of water level of reservoir. Velocity of bank landslide after failure is important for risk management of landslide. There are generally two kinds of methods in prediction of landslide velocity. One is empirical methods and the other is analytical ones. Empirical methods are usually proposed based on field observations and multiple regression analysis between velocity and frictional coefficient or travel distance of landslide. Scheidegger (1973) noted that the coefficient of friction of the slip surface was equal to the tangent of the reach angle, which was also expressed by the ratio between the vertical drop and horizontal projection of the travel distance. The frictional model between volume of landslide and coefficient of friction was given, and the coefficient of friction became progressively smaller as the volume of the sliding mass increased (Scheidegger, 1973). However, another similar parameter called excessive travel distance was proposed to evaluate landslide mobility (Hsu, 1975; Corominas, 1996). Pudasaini and Miller (2013) constructed theoretical effective Coulomb friction coefficient that described the long runout of huge landslides, rock falls, debris flows and avalanches. Based on the dynamics and occurrence conditions of 43 rapid and long run-out rock avalanches in China, a new research showed that the equivalent coefficient of friction of slip surface was affected by dynamic type, transport topography, lithology constituting the rockmass, rock-mass strength, and distance from the seismic fault (Zhang et al., 2013).

The analytical methods mainly consisted of three models. The first was lumped mass models, which assumed that landslide was a single point. The second was twodimensional models, in which the landslide was simplified based on a typical profile. The third was three- dimensional models based on irregular 3D terrain (Hungr et al., 2005). Some well-known models, which were commonly used for landslide velocity and run-out, were classified based on material properties, considering internal strength, entrainment and rheology variations (Quan, 2012). Some Models for landslide velocity usually have more complex forms because of considering air fluidization of landslide with a high speed (Kent 1966), air-layer lubrication (Shreve 1966; Shreve 1968), grain flow (Hsu, 1975; Zhang et al., 1997), self-lubrication of fused rock during landslide movement process (Erismann, 1979), momentum transfer (Van Gassen et al.,1989), buoyancy and pore pressure(Sassa, 1988; Pudasainial.et al., 2012). These models were mostly expressed by differential equations which could be solved by numerical methods such as finite difference or distinct element.

For the failed partially submerged landslide which moved into river, the hydraulic resistance is a very important factor which affects landslide velocity. Therefore, prediction of velocity of partially submerged bank landslide is still very complex and worthy of further study.

In this paper, experiments for the motion of submerged block are conducted through employing a self-designed test system. The experiments consider six blocks with different areas, and each block moves at five different speeds in water tank. The hydraulic resistances acting on the blocks are measured when they move in water tank. On the basis of

\footnotetext{
*E-mail address: wangyangcug@126.com

ISSN: 1791-2377 @ 2014 Kavala Institute of Technology. All rights reserved.
} 
Wang Yang, Tang Yang, Cao Ying, Li De-ying and Wang Wei

/Journal of Engineering Science and Technology Review 7 (3) (2014) 62 - 67

that, the velocity calculation model of partially submerged landslide is proposed.

\section{Hydraulic Resistance Experiment}

The hydraulic resistance of submerged blocks consists of water pressure acting on the front surface of blocks and water viscous resistance. Usually, the latter is much smaller than the former. Therefore, the water viscous resistance is ignored in experiment. Based on an experiment, the relationship between hydraulic resistance and velocity is analyzed.

\subsection{Experiment System}

The experiment system mainly consists of a water tank (Fig.1), a moving frame fixed over the tank with liquid level sensors (Fig.1, Fig. 2), blocks, and velocity control apparatus (Fig.3). The blocks are made of organic glass sheet because of the limited propulsion of velocity control apparatus. Liquid level sensors with a measurement range of $0 \sim 1 \mathrm{~m}$ are used for measurement of pressure head. The distance between liquid level sensor and the surface of water in tank is $0.3 \mathrm{~m}$

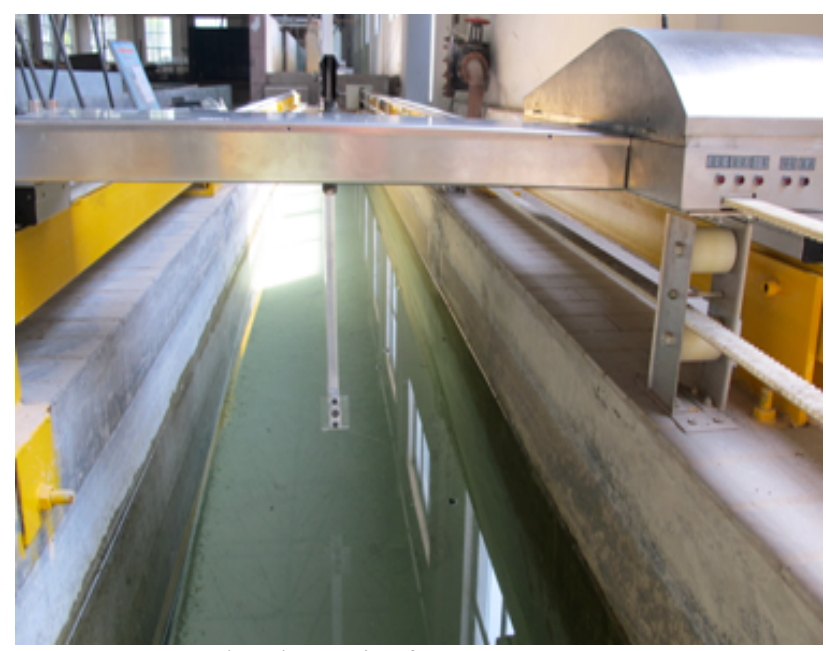

Fig. 1. A water tank and a moving frame.

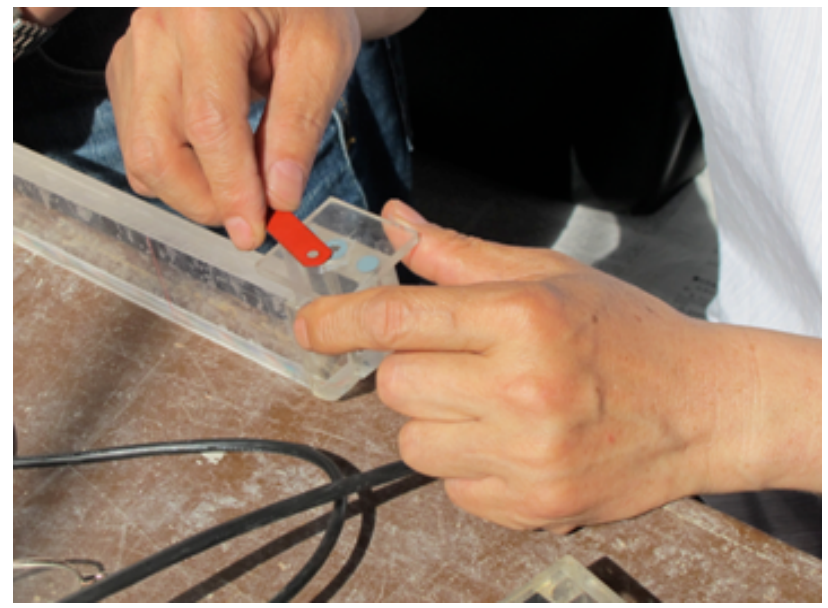

Fig. 2. Organic glass sheet and liquid level sensor

\subsection{Experiment Parameters}

Six blocks of different areas are produced, with sizes of $4 \times 4 \mathrm{~cm}^{2}$ (block 1), $4.5 \times 4.5 \mathrm{~cm}^{2}$ (block 2), $5 \times 5 \mathrm{~cm}^{2}$ (block 3 ), $5.5 \times 5.5 \mathrm{~cm}^{2}$ (block 4), $6 \times 6 \mathrm{~cm}^{2}$ (block 5), and $8 \times 8 \mathrm{~cm}^{2}$ (block 6). Five values, which are respectively $0.5 \mathrm{~m} / \mathrm{s}, 0.8 \mathrm{~m} / \mathrm{s}$,
$1.0 \mathrm{~m} / \mathrm{s}, 1.5 \mathrm{~m} / \mathrm{s}$, and $1.8 \mathrm{~m} / \mathrm{s}$, are selected as the velocities of submerged blocks.

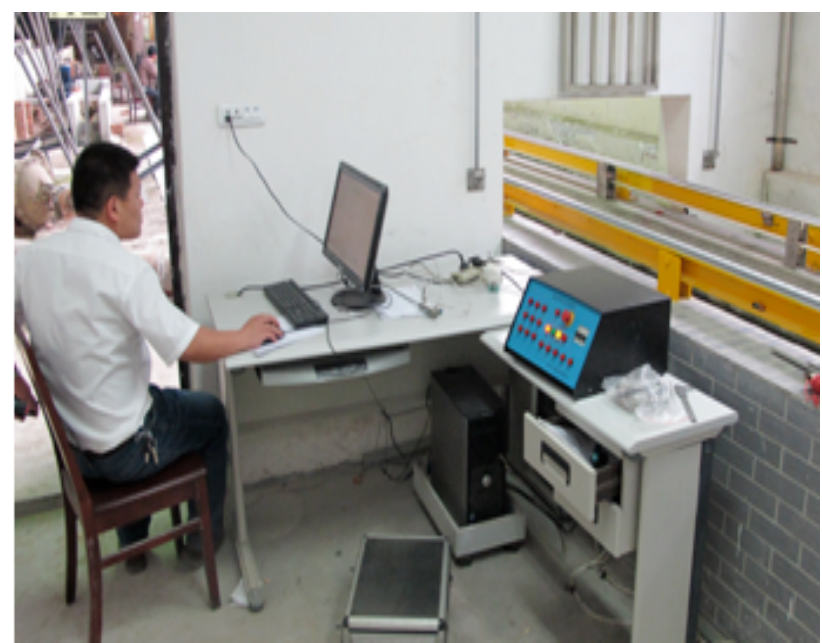

Fig. 3. Apparatus of velocity control

\subsection{Experiment Results}

Liquid level sensor can record the water head when submerged block moves at a certain velocity or stays statically in water tank, and the increment of the pressure head is defined by the water head of moving block minus that of static block in water tank.

Tab.1. Increment of pressure head

\begin{tabular}{|c|c|c|c|c|c|}
\hline \multirow{2}{*}{$\begin{array}{l}\text { Increment of } \\
\text { pressure head / } \\
\text { m }\end{array}$} & \multicolumn{5}{|c|}{ speed $/ \mathrm{m} \cdot \mathrm{s}^{-1}$} \\
\hline & 0.5 & 0.8 & 1.0 & 1.5 & 1.8 \\
\hline Block 1 & 0.012 & 0.031 & 0.051 & 0.111 & 0.160 \\
\hline Block 2 & 0.013 & 0.033 & 0.039 & 0.111 & 0.158 \\
\hline Block 3 & 0.012 & 0.031 & 0.050 & 0.116 & 0.157 \\
\hline Block 4 & 0.012 & 0.031 & 0.051 & 0.114 & 0.166 \\
\hline Block 5 & 0.013 & 0.034 & 0.045 & 0.113 & 0.160 \\
\hline Block 6 & 0.013 & 0.031 & 0.049 & 0.113 & 0.157 \\
\hline
\end{tabular}

The increment of pressure head is not related to the block front area, and increases with the increasing of block velocity (Table. 1). Table. 2 shows the ratio of incremental pressure head to square velocity of block, and the ratio is not relevant to either the block front area or block velocity if the experimental error is ignored.

Tab.2. Ratios of incremental pressure head to square speed of submerged blocks

\begin{tabular}{l|l|l|l|l|l}
\hline $\begin{array}{l}\text { The ratio of } \\
\text { pressure head to the } \\
\text { square of the speed } \\
\text { increment/ m·s }{ }^{-2}\end{array}$ & \multicolumn{5}{|c}{ speed/m·s ${ }^{-1}$} \\
\cline { 2 - 6 } & $\mathbf{0 . 5}$ & $\mathbf{0 . 8}$ & $\mathbf{1 . 0}$ & $\mathbf{1 . 5}$ & $\mathbf{1 . 8}$ \\
\hline Block 1 & 0.048 & 0.048 & 0.051 & 0.049 & 0.049 \\
Block 2 & 0.051 & 0.052 & 0.039 & 0.049 & 0.049 \\
Block 3 & 0.050 & 0.049 & 0.050 & 0.051 & 0.048 \\
Block 4 & 0.048 & 0.048 & 0.051 & 0.051 & 0.051 \\
Block 5 & 0.051 & 0.053 & 0.045 & 0.050 & 0.049 \\
Block 6 & 0.052 & 0.048 & 0.049 & 0.050 & 0.049 \\
Mean & 0.050 & 0.050 & 0.048 & 0.050 & 0.049 \\
\hline
\end{tabular}


According to Table. 2, the increment of the pressure head is proportional to the square velocity of block, which can be expressed as follow:

$\Delta h=\frac{v^{2}}{2 g}$

Where, $\Delta h$ is increment of the pressure head, $v$ is velocity of block, $g$ is acceleration of gravity.

Therefore, the total water pressure acting on the front area of the moving block consists of hydrostatic pressure and hydrodynamic pressure, which can be expressed as follow:

$P_{d}=P_{j}+\frac{\gamma_{w} v^{2}}{2 g} S$

In which, $P_{d}$ is total water pressure acting on the front area of the moving block, $P_{j}$ is hydrostatic pressure acting on front area of block, $S$ is front area of block, which is the projection area in the direction perpendicular to block velocity.

When submerged block moves in water tank, the hydraulic resistance can be given as follow:

$R=\frac{\gamma_{w} v^{2}}{2 g} S$

where, $R$ is hydraulic resistance of submerged block moving in the water tank.

\section{The Velocity Model of Partially Submerged Landslide}

\subsection{The Gravity and Water Pressure of Partially Submerged Landslide}

The partially submerged landslide includes subaerial part and underwater part, and gravity and water pressure acting on subaerial part are different from those acting on underwater part. In landslide stability analysis by means of limit equilibrium method, there are two approaches for calculation of both forces. One is that water pressure acting on underwater part can be calculated by seepage force and gravity is considered as effective weight. The other is that water pressure can be calculated by surrounding hydrostatic pressure and gravity is considered as saturated weight. The two approaches are equivalent (Mao et al. 2001; Wang et al. 2010).

\subsection{Velocity of Partially Submerged Landslide}

The shape of sliding surface is commonly curve, so method of slice is used to analyze forces acting on slices. Each slice is assumed to be rigid. The acceleration perpendicular to the direction of slip surface of the current slice is zero. The interslice resultant of the left and right forces on the current slice is assumed to incline at an angle parallel to the slip surface. The accelerations of all slices are assumed to be same at the same time.

The slice forces are shown in Figure. 4, and they can be resolved in directions both parallel and perpendicular to the slip surface. The components of all forces acting on the slice can be in equilibrium as follows:

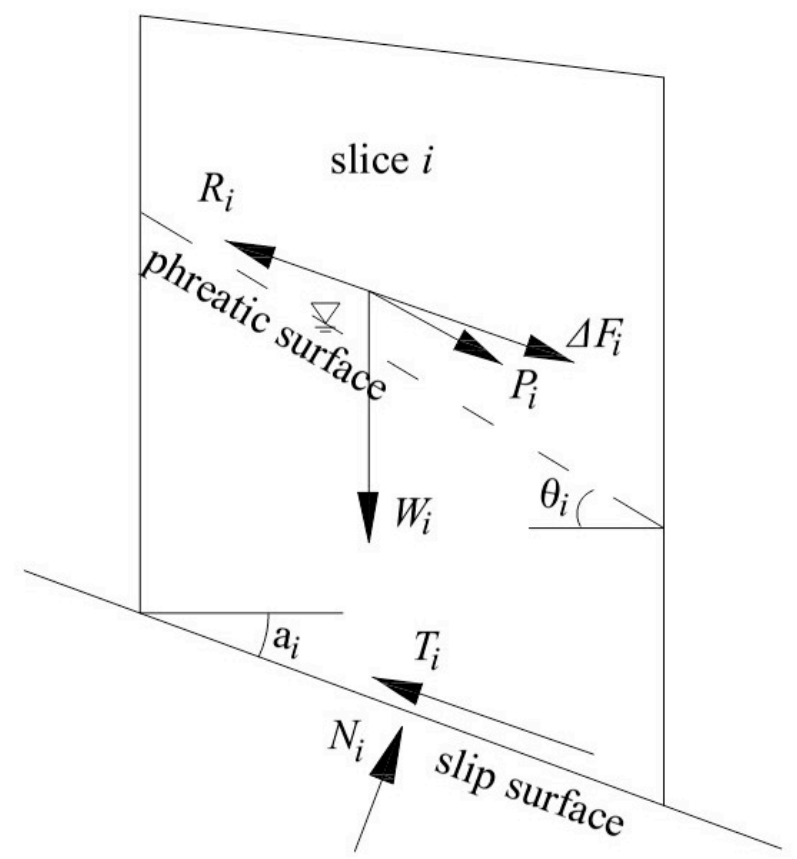

Fig. 4. Forces acting on slice

$W_{i} \cos \alpha_{i}+P_{i} \sin \beta_{i}-N_{i}=0$

and

$W_{i} \sin \alpha_{i}+P_{i} \cos \beta_{i}+\Delta F_{i}-R_{i}-T_{i}=m_{i} a_{i}$

with

$\beta_{i}=\theta_{i}-\alpha_{i}$

$T_{i}=N_{i} \operatorname{tg} \phi_{i}+c_{i} l_{i}$

$P_{i}=\gamma_{W} \sin \theta_{i} V_{i d}$

where, $W_{i}$ is weight of slice, $P_{i}$ is seepage force, which is 0 for the submerged slices, $\Delta F_{i}$ is interslice resultant of the left and right forces on the current slice, $N_{i}$ is normal force at base of slice, $\theta_{i}$ is inclination of phreatic surface, $\alpha_{i}$ is inclination of slip surface, $T_{i}$ is friction along slip surface, $R_{i}$ is hydraulic resistance of moving landslide, $m_{i}$ is mass of slice, $a_{i}$ is acceleration of slice, $c_{i}$ is cohesion of slip surface, $\varphi_{i}$ is friction angle of slip surface, $l_{i}$ is length of slice base, $V_{i d}$ is landslide volume under phreatic surface.

According to Eq.(4), we have

$N_{i}=W_{i} \cos \alpha_{i}+P_{i} \sin \beta_{i}$

By substituting Eq. (6) into Eq. (5), the following expression is derived:

$\Delta F_{i}=m_{i} a_{i}+R_{i}-W_{i} \varphi_{1 i}-P_{i} \varphi_{2 i}+c_{i} l_{i}$

with

$\varphi_{1 i}=\sin \alpha_{i}-\cos \alpha_{i} \operatorname{tg} \phi_{i}$

$\varphi_{2 i}=\cos \beta_{i}-\sin \beta_{i} \operatorname{tg} \phi_{i}$ 
For the whole landslide, $\Delta F_{i}$ is the interslice force, therefore,

$$
\sum_{i=1}^{n} \Delta F_{i}=0
$$

By substituting Eq. (5) into Eq. (8), the following expression is derived:

$$
a_{i}=\frac{\sum_{i=1}^{n} W_{i} \varphi_{1 i}+\sum_{i=1}^{n} P_{i} \varphi_{2 i}-\sum_{i=1}^{n} c_{i} l_{i}-\sum_{i=1}^{n} R_{i}}{\sum_{i=1}^{n} m_{i}}
$$

According to kinematics equation, landslide velocity can be expressed as follow:

$$
v_{i}^{2}=v_{i-1}^{2}+2 a_{i} l_{i}
$$

According to Eq. (3),

$$
\sum_{i=1}^{n} R_{i}=\sum_{i=1}^{n} \frac{\gamma_{w} v_{i}^{2}}{2 g} S_{i}
$$

By substituting Eq. (9) and Eq. (11) into Eq. (10), the following expression for velocity of partially submerged landslide can be formulated as follow:

$$
v_{i}=\sqrt{\frac{2 g b_{i} l_{i}+\left(\sum_{i=1}^{n} W_{i}\right) v_{i-1}^{2}}{\gamma_{w} S_{i} l_{i}+\sum_{i=1}^{n} W_{i}}}
$$

with

$$
b_{i}=\sum_{i=1}^{n} W_{i} \phi_{1 i}+\sum_{i=1}^{n} P_{i} \phi_{2 i}-\sum_{i=1}^{n} c_{i} l_{i}
$$

\subsection{Case Study}

The Dayantang landslide, occurred at 16:56 on June 15th, 2007, is located in Taiping Town on the left bank of Qingjiang River. It is about $600 \mathrm{~m}$ long and $10 \mathrm{~m}$ thick, with a volume of $300 \times 10^{4} \mathrm{~m}^{3}$. The average width of the landslide is $500 \mathrm{~m}$, with the biggest width of $900 \mathrm{~m}$ in the front. The elevations of the top and tongue of the landslide are $620 \mathrm{~m}$ and $225 \mathrm{~m}$ respectively (Fig.5, Fig.6, Fig.7). The Dayantang landslide consists of moderate-strong weathered rock and sloping eluvial deposits. These deposits mainly are composed of loose rubble soil with a rubble content of $67 \% \sim 78 \%$. The rubbles, which consist of limestone and muddy limestone, have an average diameter of above $0.5 \mathrm{~m}$. Bedrock of the landslide was formed in the Daye Formation of the Triassic Period, mainly composed of middle-thin layer limestone and muddy limestone with a dip direction of $252^{\circ}$ and a dip angle of $9^{\circ}$ (Yin et al. 2008).

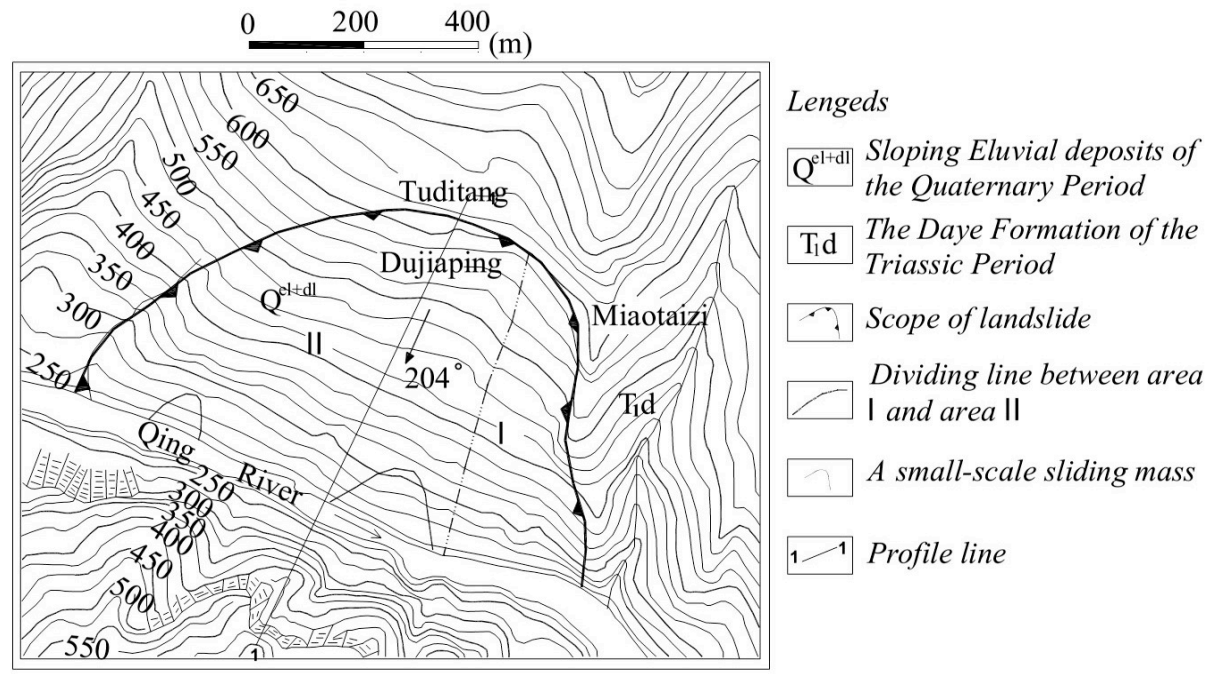

Fig. 5. Engineering geological plan of Dayantang landslide

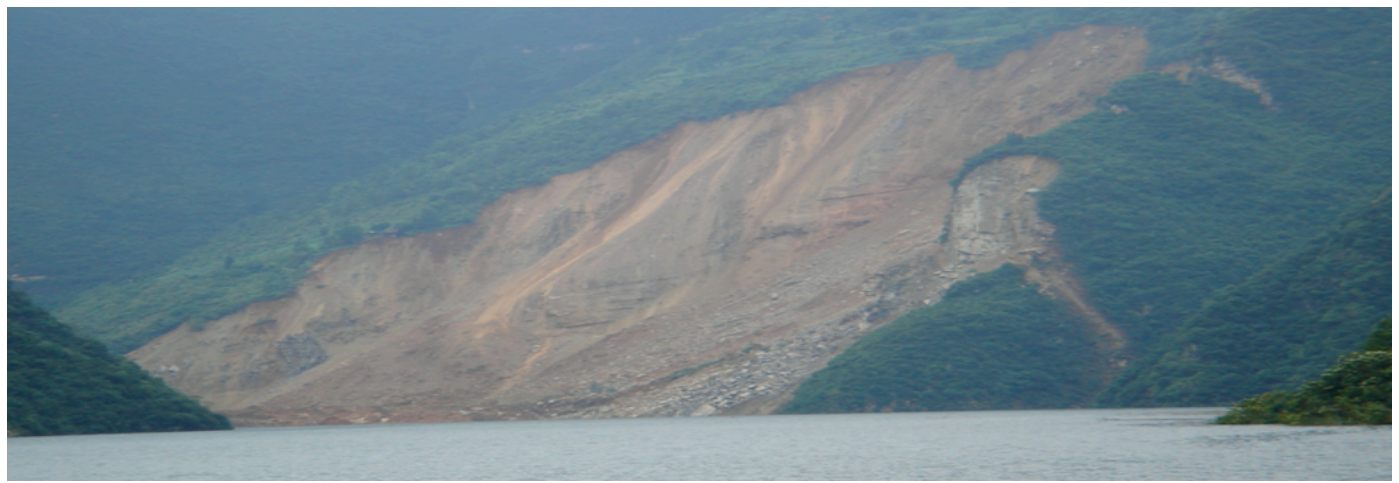

Fig. 6. Photo of the Dayantang landslide 


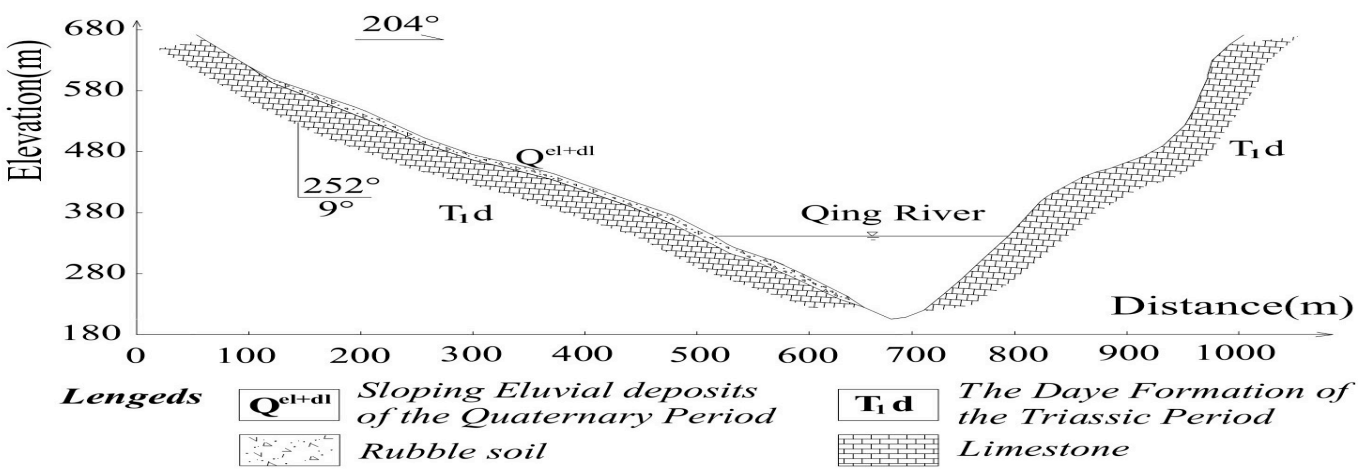

Fig. 7. The geological cross-section of the Dayantang landslide

The cohesion of slip surface is assumed to be zero when the landslide begins to move, and the friction angle is $21.76^{\circ}$. Division of the Dayantang landslide into slices is shown in Fig. 8 .

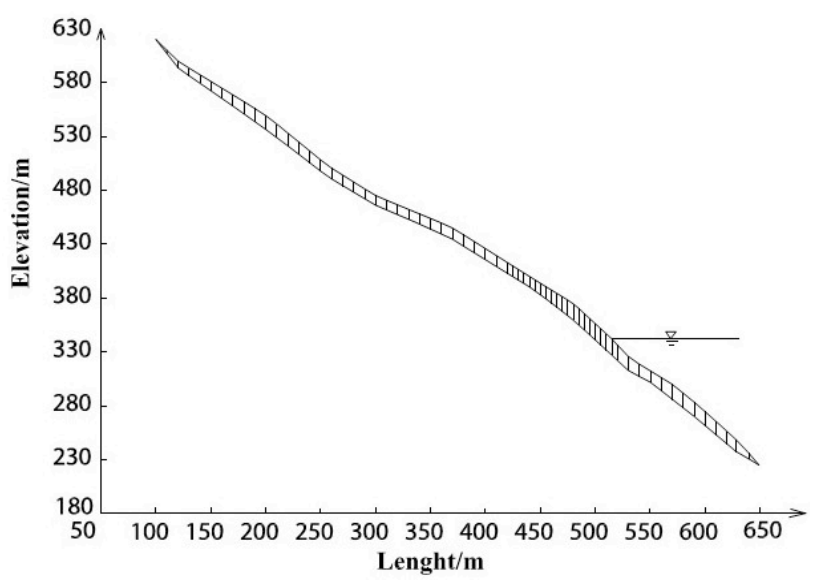

Fig. 8. Division of the Dayantang landslide into slices

In order to analyze the effect of hydraulic resistance on landslide velocity, the velocities with and without hydraulic resistance acting on the landslide are shown respectively in Fig. 9.

The maximum velocities are apparently affected by hydraulic resistance. Without hydraulic resistance, the calculated maximum velocity of the Dayantang landslide is $14 \mathrm{~m} / \mathrm{s}$, and the corresponding travel distance is about $70 \mathrm{~m}$; while the velocity with hydraulic resistance is $11.04 \mathrm{~m} / \mathrm{s}$ when travel distance is $70 \mathrm{~m}$. When considering hydraulic resistance, the calculated maximum velocity is $11.40 \mathrm{~m} / \mathrm{s}$, and the corresponding travel distance is about $50 \mathrm{~m}$. The velocity without hydraulic resistance is $13.37 \mathrm{~m} / \mathrm{s}$ when travel distance is $50 \mathrm{~m}$.

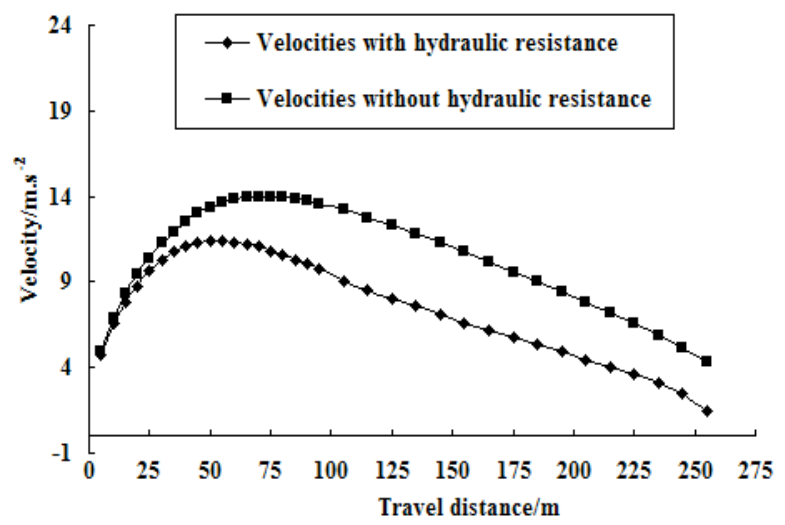

Fig. 9 Velocities of the Dayantang landslide
The maximum difference of velocity under these two conditions is $2.6 \mathrm{~m} / \mathrm{s}$, and the velocity with hydraulic resistance is reduced by $18.6 \%$ compared with that without hydraulic resistance.

The velocities with same travel distance are also affected by hydraulic resistance. The maximum difference of velocity under two conditions is $4.30 \mathrm{~m} / \mathrm{s}$ when travel distance is $125 \mathrm{~m}$, with the velocity being $12.34 \mathrm{~m} / \mathrm{s}$ and $8.04 \mathrm{~m} / \mathrm{s}$ under the conditions of considering and without considering hydraulic resistance respectively. The velocity with hydraulic resistance is reduced by $34.8 \%$ compared with that in the other condition.

\section{Conclusions}

For partially submerged landslide, hydraulic resistance is a significant factor for the velocity. An experiment system for the measurement of hydraulic resistance acting on the moving submerged blocks was established, which included a water tank, a moving frame fixed over the tank with liquid level sensors, blocks, and velocity control apparatus. Six blocks with different areas were used for experiments and each block moved at five different velocities in water tank. The water head was recorded by liquid level sensor. Test results showed that the increment of the pressure head was proportional to the square velocity of submerged block. Based on the experiment, the relationship between submerged block velocity and the hydraulic resistance was analyzed, and a hydraulic resistance model was proposed.

A formula for the velocity of partially submerged landslide was proposed based on the dynamics and kinematics equations of landslide. Taking Dayantang landslide as an example, the velocities with/without the consideration of hydraulic resistance were calculated respectively, and the effect of hydraulic resistance on landslide velocity was analyzed quantitatively. The maximum velocity considering hydraulic resistance was $18.6 \%$ less than that without considering hydraulic resistance.

The results of the paper have significant meaning in risk assessment of bank landslide and landslide- generated water wave. In order to simplify forces acting on landslide, each slice of landslide in this research was assumed to be rigid. However, landslide is deformable during movement process, and the projection area of landslide in the direction perpendicular to velocity will change with the travel distance. From this point of view, the hydraulic resistance and velocity of real landslide are different from those of rigid landslide model. Therefore, further studies on hydraulic 
Wang Yang, Tang Yang, Cao Ying, Li De-ying and Wang Wei

/Journal of Engineering Science and Technology Review 7 (3) (2014) 62 - 67

resistance and velocity of deformable landslide are needed and worthy to be carried out in later continually research.

\section{Acknowledgments}

This research work was supported by the National Natural Science Funding of China (No. 41302230), the China
Geological Survey Project (No. 1212011220173), and Open Funding of Engineering Research Center of Rock-Soil Drilling \& Excavation and Protection, Ministry of Education, China (No. 201102). Special thanks were given to Dr. Zhibing Jiang, Yangtze River Scientific Research Institute, who provided great help to experiments.

\section{References}

1. Corominas, J. "The angle of reach as a mobility index for small and large landslides", Canadian Geotechnical Journal, 33(2), 1996, pp. 260-271.

2. Erismann, T.H. "Mechanisms of large landslides", Rock Mechanics, 12(1), 1979, pp.15-46.

3. Hsu, K.J. "Catastrophic debris streams (sturzstroms) generated by rockfalls”, Geological Society of America Bulletin, 86(1), 1975, pp. 129-140.

4. Hungr, O., Corominas, J., Eberhardt, E. "Estimating landslide motion mechanism, travel distance and velocity", Proceedings of the International Conference on Landslide Risk Management, Vancouver, Canada, May-June. 2005, pp. 99-128.

5. Kent P. E. "The Transport mechanism in catastrophic rock falls", The Journal of Geology, 74(1), 1966, pp. 79-83.

6. Mao C., Li J., Duan X. "Finite element calculation on circular slip of earth slope under seepage action", Chinese Journal of Geotechnical Engineering, 23(6), 2001, pp. 746-752 (In Chinese).

7. Mueller L. "New considerations on the Vaiont slide", Rock Mechanics \& Engineering Geology, 6(2), 1968, pp. 4-91.

8. Pudasaini, S.P., Miller, S.A. "Buoyancy induced mobility in twophase debris flow", AIP Conference Proceedings, America Institute of Physics, 1479(1), 2012, pp. 149-152.

9. Pudasaini, S.P., Miller, S.A. "The hypermobility of huge landslides and avalanches", Engineering Geology, 157, 2013, pp.124-132.

10. Quan L.B. "Dynamic numerical run-out modeling for quantitative landslide risk assessment", Thesis of University of Twente, ITC, 206, 2012, pp. 1-237.

11. Sassa, K. "Geotechnical model for the motion of landslides. In:C. Bonnard(ed.)", Proceedings of the 5th International Symposium on Landslides, Lausanne, Switzerland, 1, 1988, pp.37-55.
12. Scheidgger, A.E. "On the prediction of the reach and velocity of catastrophic landslides", Rock mechanics, 5(4), 1973, pp. 231-236.

13. Shreve, R.L. "Sherman landslide, Alaska", Science, 154(3757), 1966, pp. 1639-1643.

14. Shreve, R.L. "Leakage and Fluidization in Air-Layer Lubricated Avalanches", Geological Society of America Bulletin, 79(5), 1968, pp. 653-658.

15. Van Gassen, W., Cruden, D. "Momentum transfer and friction in the debris of rock avalanches", Canadian Geotechnical Journal, 26(4), 1989, pp. 623-628.

16. Yin K., Du J., Wang Y. "Analysis on surge triggered by Dayantang landslide in Shuibuya reservoir of Qingjiang river", Rock and Soil Mechanics, 29(12), 2008, pp.3266-3270 (In Chinese).

17. Wang F., Zhang Y., Huo Z., Matsumoto T, Huang BL. "The July 14, 2003 Qianjiangping landslide, Three Gorges Reservoir, China”, Landslide, 1(2), 2004, pp. 157-162.

18. Wang Y, Zhou L, Yin K. "Research on the stability of sliding mass below the water level on the basis of water pressure around slices", Rock and Soil Mechanics, 31(4), 2010, pp. 1068-1071. (In Chinese)

19. Zhang D., Foda, M. A. "An instability mechanism for the sliding motion of finite depth of bulk granular materials", Acta Mechanica, 121(1-4), 1997, pp. 1-19.

20. Zhang M, Yin Y. "Dynamics, mobility-controlling factors and transport mechanisms of rapid long-runout rock avalanches in China”, Engineering Geology, 167, 2013, pp.37-58. 